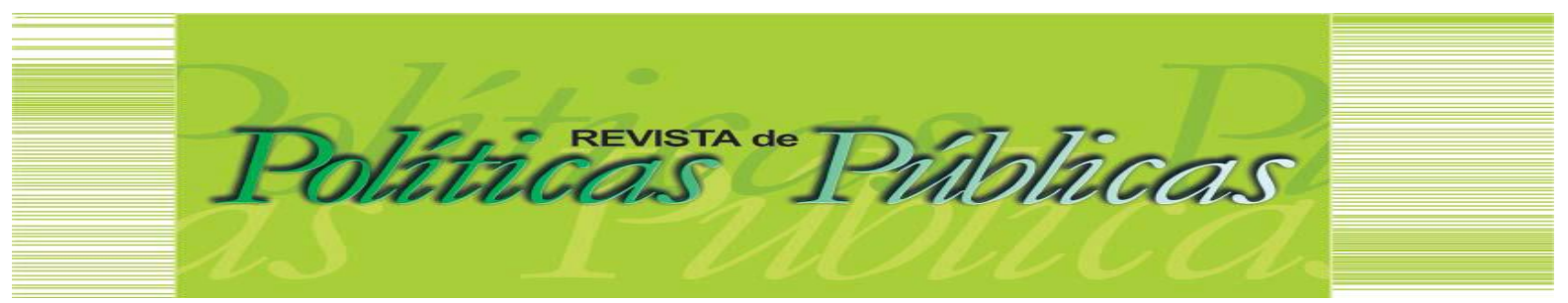

\title{
LA DIALÉCTICA REFORMA-REVOLUCIÓN EN PERSPECTIVA LATINOAMERICANA: elementos históricos para la crítica del presente
}

Silvia Fernández Soto ${ }^{1}$

\begin{abstract}
Resumen:
El artículo destaca que la revolución rusa de 1917 constituyó uno de los principales acontecimientos del siglo XX. Sus consecuencias fueron múltiples, implicando significativas transformaciones socio-económicas políticas y culturales, alimentando ideas y prácticas emancipatorias en las clases trabajadoras en todo el mundo. Resalta que el momento de crisis global actual del capitalismo, a cien años de la revolución, nos exige un análisis crítico del proceso socio-histórico concreto del último siglo, observando las particularidades de las experiencias latinoamericanas, las continuidades, rupturas, tensiones, reformas y revoluciones. Así, nos parece central superar perspectivas abstractas, uniformes y simplificadoras de nuestra realidad. Considera todavía que, por el contrario, es necesario alimentar análisis concretos e históricos que rompan la naturalización de nuestras realidades y enriquezcan prácticas de transformación social.
\end{abstract}

Palabras-claves: América Latina. Reforma. Revolución. Dialéctica. Neoliberalismo. Desigualdad social.

THE DIALECTIC REFORM-REVOLUTION IN THE LATIN AMERICAN PERSPECTIVE: historical elements for the critique of the present

\begin{abstract}
:
The article highlights that the Russian Revolution of 1917 was one of the main facts of the twentieth century. Its consequences were multiple, implying significant socio-economical, political and cultural changes, feeding ideas and emancipatory practices in the working class worldwide. It points out that the timing of the current global crisis of capitalism, after a hundred years of the revolution, requires a critical analysis of concrete socio-historical process of the last century, observing the particularities of Latin American experiences, continuities, ruptures, tensions, reforms and revolutions. Thus, it seems to us overcome abstract central prospects, uniforms and simplistic of our reality. Still considers, that, on the contrary, it is necessary to feed concrete and historical analysis, break the naturalization of our realities and enrich practices of social transformation.

Keywords: Latin America. Reform. Revolution. Dialectics. Neoliberalism Social inequality.
\end{abstract}

Artigo recebido em: 29/08/2018 Aprovado em: 28/03/2019 DOl: http://dx.doi.org/10.18764/2178-2865.v23n1p372-388

\footnotetext{
1 Licenciada en Trabajo Social. Doutora pela Pontífica Universidade Católica de São Paulo (PUC-SP). Professora Titular da Facultad de Ciencias Humanas (FCH) da Universidad Central (UNICEN) e investigadora de Consejo Nacional de Investigaciones Científicas y Técnicas (CONICET) do Programa de Investigación y Estudio sobre Política y Sociedad (PROIEPS)-FCH-UNICEN. Endereço Paraje Arroyo Seco. Campus Universitario-FCH-UNICEN. Endereço: Calle/Santivañes, $n$. 216. E-mail: silviafernandezsoto@gmail.com
} 


\section{INTRODUCCIÓN}

La revolución rusa de 1917 es el elemento central para entender el siglo XX. Implicó significativas transformaciones socio-económicas políticas y culturales, alimentando ideas y prácticas emancipatorias en las clases trabajadoras. El momento de crisis global actual del capitalismo, a cien años de la revolución, nos exige un análisis crítico del proceso socio-histórico concreto del último siglo, observando las particularidades de las experiencias latinoamericanas, las continuidades, rupturas, tensiones, reformas y revoluciones. Nos parece central superar perspectivas abstractas, uniformes y simplificadoras de nuestra realidad. Por el contrario, es necesario alimentar análisis concretos e históricos, que rompan la naturalización de nuestras realidades y enriquezcan prácticas de transformación social. Este objetivo, si bien es ambicioso, nos coloca en el desafío de reconstruir los trazos generales de la coyuntura latinoamericana con el objetivo de visibilizar los proyectos socio-económicos y políticos que están en marcha en el subcontinente; las disputas y tensiones desplegadas y el significado socio-histórico de los avances de un proyecto de sociedad contrarreformista y reaccionario, con consecuencias devastadoras para las experiencias de nuestros pueblos.

Encaramos el debate sobre la cuestión de reforma y revolución en perspectiva latinoamericana, desde nuestro presente histórico. Colocamos la cuestión de América Latina como totalidad concreta, que constituye en su movimiento histórico una realidad específica y diversa. Este recorrido nos permite reconstruir elementos históricos para reflexionar sobre reforma y revolución en nuestro presente a partir de nuestra experiencia concreta.

\section{AMÉRICA LATINA EN PERSPECTIVA HISTÓRICA: dialéctica de la desigualdad}

América Latina expresa las promesas incumplidas de la retórica de la modernidad capitalista, la mistificación de las promesas civilizatorias occidentales y, su existencia concreta interpela un discurso universalizante que homogeiniza, deshistoriza, se asienta en falsas dicotomías, y en un pensamiento etapista y lineal. Pensamiento dominante que invisibiliza los conflictos y luchas de clases. Pensamiento acorde con la racionalidad del capital y que oculta el papel histórico asignado a América Latina.

Ese pensamiento se encuentra instalado aún hoy, se incluye en lo que podemos denominar el pensamiento dominante en gran parte del desarrollo histórico de nuestra región, sobre todo en el ámbito académico, planteando como horizonte el ideal de los capitalismos desarrollados. Esa concepción dominante no da cuenta de las realidades específicas, ni de sus procesos de lucha, ni de las relaciones históricas desiguales en las cuales la región construye su(s) identidad(es). Imbuida de un pensamiento 
eurocéntrico, se asienta en una concepción evolucionista, lineal y etapista, imposibilitada de reconocer un "[...] desarrollo desigual combinado de las historias de las sociedades." (GRÜNER, 2010, p. 34-35).

Los análisis sobre América Latina formulados por el pensamiento académico dominante y organismos internacionales se basan y sostienen la idea de una supuesta falta de madurez de la región respecto de las formas que el capitalismo se presenta en naciones 0 en regiones del llamado mundo central, primer mundo, mundo desarrollado. Son comunes las afirmaciones que hablan de reformas económicas insuficientes, instituciones políticas que no se han consolidado o culturas políticas que no terminan de alcanzar niveles adecuados de desarrollo.

Subyace a este pensamiento la idea de una brecha no cubierta respecto de lo que acontece en algún modelo predominantemente europeo o en Estados Unidos, que es presentado como modelo a seguir. Por supuesto, esta cosmovisión omite ubicar a las relaciones imperialistas como causa principal del desarrollo histórico en nuestros países. El desarrollo del capitalismo engendra en su movimiento la dialéctica homogeneización/diferenciación; al mismo tiempo unifica y diferencia los espacios geográficos a escala global, produce en su proceso histórico desarrollos desiguales combinados. La historia del capitalismo a escala global, implica en cada temporalidad concreta desarrollos geográficos desiguales. Es inherente a su desarrollo la definición de soluciones espaciales al proceso de valorización. (HARVEY, 2007a, 2007b). La producción geográfica capitalista, desigual y contradictoria, al mismo tiempo contiene la tendencia a la generalización de la ley del valor y la diferenciación creciente del espacio y las formas de realizar los trabajos concretos. De esta manera el capitalismo va construyendo soluciones espaciales, que engendran desigualdades, especializaciones particulares enlazadas a procesos de valorización global, expresando en esa construcción histórica resultante relaciones e intereses de clases multi-escalas¹.

En ese sentido, la historia regional se hace inteligible en el marco de las relaciones establecidas en el seno del capitalismo como un sistema mundial, las que de manera simultánea propician distintas formas de despliegue capitalista -centros y periferias como uno de sus nombres más frecuenteslas cuales -bajo lógicas generales y comunes- presentan ciertas particularidades, engendrando al mismo tiempo desarrollos desiguales y combinados.

El problema del análisis sobre América Latina no es, por tanto, ofrecer un listado de supuestas tareas pendientes, sino de dar cuenta - en el seno de aquellas relaciones capitalistas - de las formas particulares en las cuales la región se constituye. De esta manera nos centramos en comprender la concreción y no el deber ser de nuestra región. Y su existencia desvela la contracara del progreso y la civilización capitalista. La abundancia en los centros imperiales, sus grandes revoluciones políticas, las 
poderosas transformaciones industriales, la ebullición productiva y el progreso, todo lo de humanidad y bienestar que allí se gestaba, tenía como contracara el colonialismo, la expoliación, el saqueo de riquezas y el exterminio de pueblos originarios, el montaje de una organización colonial de sometimiento, desprecio y despojo que reclamó, además, arrasar con numerosos pueblos de África, trasladados como esclavos a plantaciones y minas de la región, sometidos a condiciones inhumanas que provocaron miles de muertos (OSORIO, 2014), y sentaron las bases de un capitalismo basado en la superexplotación de la fuerza de trabajo (MARINI, 1972, 1973, 1978, 1996).

Al mismo tiempo, a dos siglos de la constitución de naciones formalmente independientes, se exhibe la disociación entre crecimiento y bienestar, desarrollo e igualdad. Por el contrario, América Latina sigue siendo uno de los principales territorios en el mundo de productores de pobres, donde la desigualdad y el sufrimiento son experiencias prácticas presentes, reflejando las situaciones de vida de la mayoría de la población. Junto a esa historia de despojo, América Latina presenta una historia rica de resistencias, luchas, revoluciones y sublevaciones.

Fue el proceso de valorización capitalista lo que estimuló las revoluciones en Haití y México. La revolución de los esclavos en Haití puso de manifiesto los procesos de negación que sostenían y hacian posible las consignas universales sobre libertad, igualdad y fraternidad de la Revolución Francesa de 1789. "La modernidad capitalista no podría haberse consolidado sin la instrumentación de la esclavitud afroamericana en tanto proyecto económico y político universal." (GRÜNER, 2010, p. 35). América Latina y el Caribe se constituyen en un observatorio de las patologías de la racionalidad instrumental, donde las expresiones de la cuestión social no son una desviación de la modernidad sino su realización, expresando la dialéctica desigual que engendra.

La revolución campesina en México de 1910 antecede a la primera revolución obrerocampesina triunfante, la de los soviets, la de los bolcheviques y Lenin; nos muestra el escenario de la periferia capitalista como espacios geográficos en donde aquellas revoluciones tenderán a implosionar. El peso del campesinado indígena y de los trabajadores agrícolas de las haciendas en las movilizaciones y en la constitución de los ejércitos rebeldes fue la respuesta al creciente proceso de expropiación de tierras de comunidades y pueblos por parte de los terratenientes, así como a las miserables condiciones de existencia a las que se condenaba a aquellos trabajadores, al igual que a los que trabajaban en minas, ferrocarriles y otros servicios que construían la urbanización capitalista, con el objetivo de generar beneficios bajo el primer patrón exportador. (OSORIO, 2014). 
La Revolución Cubana², en el contexto de un mundo dividido por la Guerra Fría y geográficamente cerca del centro imperialista del sistema, gravitará e impactará no sólo en su experiencia particular, sino también en toda la región ${ }^{3}$. La Revolución Cubana, abre un nuevo escenario. Recupera la particularidad de América Latina como territorio geográfico de interpelación del orden imperante. Se enlaza en este sentido con la revolución de Saint-Domingue (Haití) de 1791-1805, encabezada por esclavos, y que culmina con la independencia y con el fin del esclavismo; y la Revolución Mexicana de 1910-1915, que abrió el ciclo revolucionario mundial en el siglo XX, el siglo corto al decir de Hobsbawm, que culmina con la derrota del llamado socialismo real en 1989.

En las décadas del 40-50 del siglo XX, en el contexto de la segunda posguerra mundial, se desarrollan en la región en un contexto de lucha de clases, complejas experiencias reformistas, de transformación social ${ }^{4}$, que implican una dialéctica de cambio y restauración capitalista ${ }^{5}$ la reconfiguración de las relaciones nacionales e internacionales, que implicó complejos procesos centrados en el mercado interno. Esas experiencias provocan la respuesta imperialista y oligárquica de las clases dominantes, desencadenando procesos regresivos, antipopulares y dictatoriales en la región.

3 REACCIÓN, IMPOSICIÓN Y DESARROLLO DEL NEOLIBERALISMO EN AMÉRICA LATINA: apertura del periodo contrarrevolucionario en la Región

La década del setenta del siglo XX, nos muestra la sangrienta reacción dominante en un contexto global de crisis capitalista ${ }^{6}$. Se instalan múltiples dictaduras cívico-militares, que desplegaron políticas represivas y reaccionarias contra las luchas populares y los avances de los gobiernos nacionalistas y populares. De esta manera se inicia un período contrarrevolucionario y contrarreformista, caracterizado por la represión a la organización y lucha de las clases trabajadoras y el despojo de conquistas históricas alcanzadas?.

En ese contexto, tras algunos intentos golpistas fallidos, finalmente la vía chilena al socialismo ${ }^{8}$ es violentamente clausurada a través de un golpe militar en septiembre de 1973, inaugurando un extenso proceso contrarrevolucionario, en ese país y la región. El golpe militar expresó la táctica represiva dominante para enfrentar la organización popular, violando la Constitución, las leyes y la configuración del Estado y sus instituciones.

En los setenta se cubre de dictaduras militares la casi totalidad de los países del Cono Sur latinoamericano en continuidad con el golpe militar en Brasil de 1964, alcanzando en los años ochenta a gran parte de Centroamérica, adquiriendo forma y contenido el periodo contrarrevolucionario en la región. 
Las nuevas dictaduras no sólo fueron una respuesta represiva y reaccionaria a los proyectos populares; fueron también, las constructoras de nuevos proyectos de reorganización económica, política, ideológica, estableciendo las bases para que posteriormente gobiernos civiles consolidaran la tarea con estrategias de legitimación bajo democracias restringidas.

Con la impronta de políticas económicas neoliberales, comenzó a tomar forma en los años setenta y ochenta en la región la inserción al mercado mundial, bajo la forma dominante de un patrón exportador, el de especialización productiva. El denominador común de este profundo proceso de reestructuración productiva será una agresiva política contra el mundo del trabajo, el derrumbe de salarios y de prestaciones sociales, el fortalecimiento de una franja monopólica del capital local y una más estrecha asociación con el capital extranjero, proceso alentado por el traspaso de importantes empresas estatales a favor del capital privado, y el estrechamiento de lazos comerciales y aperturas hacia el mercado mundial que se profundiza en los años noventa.

De esa manera, los procesos de transición a la democracia se desarrollan en este contexto condicionados por la nueva organización económica y el correspondiente disciplinamiento de la población trabajadora, incidiendo en el rediseño de la arquitectura estatal con criterios de selectividad estructural acordes a los intereses de las clases dominantes. En un contexto de tensiones, y luchas por los derechos políticos y sociales, desde los sectores hegemónicos se busca otorgar nuevas bases de legitimidad al mando político bajo modalidades compatibles con el neoliberalismo imperante. Propugnando, así, que las nuevas experiencias de aperturas democráticas se reduzcan a democracias formales. Así, se reduce la política a lo que en términos gramscianos se denomina pequeña política, es decir, sin la capacidad de incidir en las cuestiones centrales que definen la vida en común.

Si bien los años de 1990 constituyen la reafirmación del proyecto neoliberal en América Latina, al mismo tiempo son expresión de resistencias y luchas bajo diversas formas organizativas que alimentaron la construcción de una multiplicidad de identidades colectivas. Mineros, campesinos, indígenas, estudiantes, trabajadores y pobres urbanos, subempleados y desempleados son los sujetos principales de esta nueva etapa, los que hacen uso de variadas formas de lucha y confrontan al poder en grados diversos 9 .

Desarrollaremos a continuación estos núcleos problemáticos: qué expresa y qué significa la consolidación del proyecto neoliberal en América Latina y qué resistencias y luchas se despliegan en el continent; qué agenda civilizatoria se construye desde abajo, y qué implicancias tiene en términos históricos para el debate reforma y revolución en América Latina en nuestro tiempo presente. 


\section{RECONFIGURACIÓN DE LA INSERCIÓN SUBORDINADA DE AMÉRICA LATINA BAJO EL PROYECTO NEOLIBERAL}

La instalación del neoliberalismo en la región fue a sangre y fuego, a través de un nuevo autoritarismo que tuvo como puntos de apoyo centrales el pasaje desde el desarrollismo hacia el liberalismo - en lo económico -, el desarrollo de la Doctrina de la Seguridad Nacional para el combate del enemigo interno, la negación de la política como conflicto social y, por último, una nueva subordinación a los intereses y preceptos de Estados Unidos - en lo político - (ANDERSON, 1997; BORÓN, 2003).

Ese ciclo político constituye una ofensiva de las clases dominantes a escala nacional e internacional ante el avance político y material de las clases subalternas que ponían en cuestión la hegemonía del desarrollismo clásico en la región o lo re-definían desde una perspectiva popular y antiimperialista.

La consolidación del capital financiero implica el territorio latinoamericano, la extensión de los procesos de privatización y de saqueo. La acumulación por desposesión se constituye en un rasgo decisivo del capitalismo global, constituyendo la privatización un elemento central de este proceso. Sobre el carácter destructivo de la lógica de acumulación financiera en esa fase de desarrollo capitalista se consolida la estrategia doble de sobreexplotación del trabajo y la naturaleza. (HARVEY, 2007a, 2004). Se produce una reconfiguración espacio-temporal en el mundo capitalista, caracterizado por transformaciones radicales en el plano tecnológico y organizacional del proceso productivo y en la re-configuración de la estatalidad, lo cual implica una re-organización de las escalas (global-nacional-local) en las que se inserta en el desarrollo geográfico desigual que integra.

Concentración económica, centralización del capital, distribución regresiva del ingreso, privatización de las empresas públicas, reorientación regresiva de la intervención del Estado, imponiéndose criterios de focalización, selectividad estructural negativa, descentralización, desconcentración subsidiaria y mercantilización son las tendencias generales que se consolidan desde mediados de la década del setenta, en un contexto ideológico reaccionario con consecuencias a largo plazo. En ese contexto se imponen los denominados ajustes estructurales, los cuales le otorgan un nuevo perfil a las políticas diseñadas por los Estados nacionales, conformando una nueva matriz de relaciones entre el Estado y la sociedad civil. Esas transformaciones generales modifican sustancialmente la composición y las condiciones materiales de vida de las clases trabajadoras.

Ese proceso global adquiere particularidades en cada experiencia nacional, en función de los desarrollos históricos específicos y las luchas de clases y correlaciones de fuerza resultantes en cada 
territorio nacional, que se materializan en determinadas formas de desarrollo e intervención social del Estado.

5 DIALÉCTICA DEL PROCESO NEOLIBERAL EN EL SIGLO XXI: resistencias, inflexiones y continuidades estructurales

El inicio del siglo XXI nos muestra en América Latina el despliegue de distintos proyectos nacionales de desarrollo autodenominados incluyentes, progresistas, los cuales se fueron edificando en procesos de cuestionamiento al neoliberalismo aunque sobre las bases instauradas por el mismo. Las reorientaciones que implicaron estos proyectos de desarrollo se explican por el movimiento ascendente de las luchas sociales que cuestionan abiertamente a fines del siglo XX la orientación neoliberal ${ }^{10}$, en un contexto regional recesivo y de crisis económica. Se cuestionan las políticas neoliberales inspiradas en el Consenso de Washington, promoviendo la emergencia de nuevos principios de la intervención social: la predominancia de lo público, la desmercantilización de los bienes y servicios sociales, la defensa de bienes naturales, la aspiración de garantías universales a través del reconocimiento de derechos históricamente conquistados, entre otras cuestiones de una agenda que pretende forjarse desde abajo.

Aunque lejos de concretarse, esas reivindicaciones al inicio del siglo XXI señalan y marcan inflexiones con la hegemonía neoliberal, expresan resistencias a la subalternización desplegada a fines del siglo XX, y despliegan una multiplicidad de prácticas antagonistas (MODONESI, 2008) como expresión de la negación del orden existente impuesto. En este marco global, América Latina se coloca como uno de los territorios de resistencias y búsquedas de alternativas al capitalismo neoliberal a nivel global ${ }^{11}$.

Pese a esas inflexiones que suponen esos proyectos denominados progresistas, incluyentes, neodesarrollistas ${ }^{12}$, los mismos se construyen sobre continuidades estructurales con el neoliberalismo; permanece el carácter transnacional del capital que hegemoniza el proceso de acumulación en la mayoría de los países de la región y al mismo tiempo se reeditan con particularidades en cada experiencia nacional formas de la dependencia vinculada a la producción de commodities para la exportación.

En síntesis, el crecimiento sostenido de los proyectos de desarrollo desplegados no logró romper con los rasgos estructurales dominantes de la concentración de los ingresos y riquezas, bajo un esquema extranjerizado de las economías y no consiguieron alterar significativamente un patrón distributivo regresivo y desigual.

Podemos decir entonces que si bien los procesos de rebelión de fines de siglo XX y principios del XXI implicaron la impugnación desde abajo (en términos gramscianos desde el interés del pueblo) del 
proyecto hegemónico neoliberal, resquebrajando sus fundamentos legitimantes y sus intervenciones prácticas, el período que se despliega a partir de esos años críticos se caracteriza también por la permanencia de una herencia activa neoliberal en la configuración de la sociedad: la predominancia del gran capital transnacional, asociada a la continuidad histórica del saqueo de las riquezas naturales, junto con la configuración estructural de la precarización e informalidad de la fuerza de trabajo, bases firmes para reimpulsar un nuevo avance del proyecto neoliberal.

Esos elementos dan cuenta de la complejidad de la evolución de la configuración económicosocial, en donde se entrelazan el cuadro crítico de deslegitimación del proyecto neoliberal, promoviendo inflexiones y las recreaciones de continuidades con el período anterior con políticas de clara impronta liberal. Las experiencias progresistas/neo desarrollistas desplegadas en la primera década del siglo XXI expresan, con sus particularidades, esa tensión y exhiben sus límites y sus asfixias, debilidades y agotamientos.

Aprehender esa complejidad de continuidades, inflexiones y cambios en el proceso de determinaciones históricas, nos permite observar los fenómenos sociales como componentes del movimiento de la sociedad capitalista como totalidad concreta. El ciclo progresista surge de rebeliones populares que modifican las relaciones de fuerza. Promueve mejoras sociales, conquistas democráticas, y frenos discursivos y prácticos a las relaciones imperialistas, aunque no lograron establecer proyectos de canalizar las rentas agro-exportadoras hacia actividades productivas. Si bien el gasto social y la extensión de políticas sociales permitieron distender la protesta y garantizar pisos mínimos de reconocimiento a sectores históricamente relegados, el descontento y malestar se extendió bajo los gobiernos de centroizquierda, habilitando la ascensión de gobiernos de derecha.

\section{IMPULSOS REACCIONARIOS Y EL DESPLIEGUE DE CONTRARREFORMA RESTAURADORAS EN AMÉRICA LATINA}

Vivenciamos una reacción burguesa que pone en cuestión los equilibrios de compromiso establecidos en la etapa progresista, neodesarrollista. La restauración burguesa exhibe el histórico antirreformismo de clase y expresa avances del proyecto neoliberal. Expresa desestructuraciones narrativas y prácticas de los proyectos progresistas. Los procesos de reflujo muestran los límites históricos de esos procesos y la redefinición bajo esta ofensiva de los procesos de lucha de los sujetos subalternos. El triunfo electoral de una coalición de derecha en Argentina; el desarrollo exitoso del golpe parlamentario en Brasil; y el encarcelamiento del ex presidente Lula da Silva; el triunfo de un ex militar en las elecciones 
de octubre 2018, la derrota en el referéndum habilitante de la reelección de Evo Morales; y las disputas actuales por la continuidad de su liderazgo como presidente, nos muestran el avance conservador en la región, alcanzando en algunas experiencias a controlar el aparato gubernamental.

En las experiencias de avance de restauración conservadora, se observa que la intervención Social del Estado se plantea como una lógica subsidiaria mínima dirigida a la creciente masa de trabajadores repelidos y constituidos en población sobrante para los intereses del capital, transfiriendo ingresos mínimos con condicionalidades. Se despliega una pedagogía de la asistencia individual envuelta en los términos de emprendedorismo, capital humano, activación social, condicionalidades, merecimiento y esfuerzo individual, que recrea las históricas lógicas de la responsabilización individual de los pobres en el capitalismo, reestableciendo nuevas lógicas de subalternidad y disciplinamiento.

Las clases dominantes despliegan con fuerza destructiva la restauración de su dominación directa, demonizando las experiencias progresistas, erosionando argumentos y prácticas que materializan derechos y garantías sociales. Asistimos a las iniciativas mundializadas de restauración del capital que cuestionan las experiencias progresistas y los pactos que sustentaban, para reeditar nuevamente la retórica y práctica neoliberal, como estrategia dominante de enfrentamiento de la crisis.

Sobre los elementos de austeridad y gobernabilidad, despliegan los lineamientos neoliberales para asegurar sus intereses de clase, desprotegiendo el trabajo, transformando servicios públicos en negocios, ampliando los espacios de valorización capitalista a través de la mercantilización, reduciendo los planteles de trabajadores estatales bajo argumentos de desprestigio y desprecio del Estado y lo público, reduciendo el poder adquisitivo del salario, devaluando la fuerza de trabajo en general. En los contextos recesivos e inflacionarios promovidos por los gobiernos de derecha, disminuye la capacidad de compra de los sectores trabajadores, impactando en los sectores más empobrecidos, extendiendo y profundizando su pobreza. Alentando, así, la construcción de una base social conservadora y reaccionaria. Pretenden continuar y profundizar los procesos de contrarreforma liberal del Estado iniciados en los años noventa, desprestigiar las ideologías del trabajo, las conquistas y agendas emancipatorias de las mujeres, y de diferentes colectivos que luchan por su reconocimiento y por la construcción de relaciones igualitarias renovando resistencias y recreando prácticas y experiencias emancipatorias en clave latinoamericana. Esa relación restauradora se organiza sobre algunos tópicos centrales, la idea de combate a la corrupción, austeridad fiscal, preservación de la familia, asentada en relaciones patriarcales, portadores de nociones conservadoras y vetustas de familia, juventud, niñez. 
El cuadro desplegado genera sufrimiento, malestar, descontento, indignación, miedo, disciplinamiento, aislamiento. En ese cuadro hay resistencias y diversas expresiones de rebeldías sociales, muchas veces desconectadas de un explícito proyecto de sociedad.

Ese descontento y malestar general si no se politiza reafirma una cultura de la resignación, que puede ser instrumentalizado por la programática conservadora, sirviendo de sustento a políticas represivas y de criminalización. Frente a la retracción de las políticas de garantías sociales, se incrementa el uso de tecnologías sofisticadas represivas de control de las poblaciones, expresando el despliegue represivo del estado, en sus más diversas formas (propuestas legislativas para bajar la edad de punibilidad de los jóvenes, aumento de la población carcelaria, aumento de efectivos policiales, aumento del presupuesto e inversión en tecnologías represivas afectando otras áreas estatales, despliegues de protocolos de acción anti piquetes, muertes, desapariciones). Se crea, así, una sensación de inseguridad y la instalación de un estado de control extendido y poroso en la sociedad. Ante ese cuadro de situación es necesaria la politicidad del descontento y de las rebeliones y luchas sociales, que opere en un sentido de agregación constructiva y no de fragmentación y dispersión.

7 CONCLUSIONES: dialéctica entre reforma y revolución a partir de nuestra experiencia concreta. Elementos históricos para el presente

En función de lo desarrollado es necesario realizar algunas precisiones en torno al uso de diferentes términos: revolución pasiva, reforma, contrarreforma, y procesos revolucionarios.

La noción de revolución pasiva es un concepto acuñado por Gramsci para referirse a procesos complejos de formación y dinámica del moderno estado burgués (la restauración napoleónica, el fascismo, el denominado americanismo), cuyo rasgo distintivo es la combinación de procesos de restauración (reacciones conservadoras a las transformaciones populares) y de renovación (procesos que incorporan algunas demandas como concesiones) ${ }^{13}$.

A diferencia de un proceso revolucionario popular, que se gesta y desarrolla desde bajo; que construye conquistas promoviendo procesos de reivindicación y conciencia colectiva; una revolución pasiva combina restauración y renovación por lo alto, y una progresividad impuesta por demandas de grupos sociales subalternos (de abajo), en función de las correlaciones de fuerza.

Por el contrario, hablar de contrarreforma implica elementos de restauración del orden y regresividad. Predomina la reacción. 
Esas categorías expresan procesos históricos, no deben ser utilizadas en términos abstractos. En tal sentido, no podemos pensar en los procesos de reforma y/o revolución sin pensar en las experiencias concretas. No son solamente problemas teóricos; remiten, también, a situaciones de vida concretas. ¿Cómo superar la barbarie en la que nos encontramos? ¿Cómo construir una agenda desde abajo que se coloque como desafío la superación de la explotación y la desigualdad, la destrucción de la naturaleza y la humanidad?

Sin duda, el momento que atravesamos expresa un proceso reaccionario que contiene la recomposición de la tasa de ganancia sostenida con más explotación, sufrimiento, despojo. No es una catástrofe inevitable. Es una realidad histórica construida, que condensa relaciones sociales, históricas y, por lo tanto, no eternas, modificables.

El cuadro de situación que delinea ese movimiento reaccionario regresivo nos interpela, nos exige la discusión de estrategias, de tácticas, de proyectos de sociedad. Que adquieren concretud, también en una dimensión espacio temporal. Adecuaciones tácticas y estratégicas, con rebeldías organizadas que superen el espontaneismo, que se articulen en un sentido de cambio radical, de emancipación humana. Esto supone romper la pasividad, disputar la iniciativa política para dirigir los cambios.

La experiencia nos muestra que el neoliberalismo no deja espacio para garantizar los derechos sociales; por el contrario, los erosiona, los cuestiona, los desarma, los elimina. En un sentido permanente de de-construcción de reconocimientos históricos conquistados por la economía política de la clase trabajadora en el desarrollo de la sociedad capitalista. La de-construcción que implica los procesos de contrarreformas significa la restauración plena de la economía política del capital.

Reforma y revolución han estado en la experiencia histórica dialécticamente articuladas, en la construcción de una nueva hegemonía anticapitalista. En tal sentido la revolución es un proceso de cambio radical, de construcción de una nueva hegemonía, de un nuevo proyecto de sociedad, donde el objetivo sea la emancipación humana y no solo la emancipación política, que la historia nos mostró que se queda en un plano de proclamación y no de efectivización de los derechos.

Es necesario, desde las clases trabajadoras, elaborar un proyecto de Estado y una concepción propia de sociedad, de manera tal de construir una fundamentación teórica con la solidez y vitalidad necesaria para revertir la subordinación ideológica de la cultura dominante, que genera una actitud de pasividad moral y política.

La construcción de ese proyecto ético-político supone múltiples rupturas con el estado de pasividad que coloca a los sujetos como receptores, con las concepciones mecanicistas y utilitaristas y con 
las relaciones de subalternización ${ }^{14}$. Eso exige tornar el consenso pasivo en consenso activo, en instancia consciente y crítica. La conciencia se liga a la experiencia vivida, y, en ese sentido, es social e histórica y no abstracta y dada. Supone un proceso de construcción colectivo e interactivo.

Los procesos revolucionarios envuelven procesos de politización, disruptivos, que provocan cambios de abajo hacia arriba, perturbando las relaciones fundamentales de la sociedad, provocando nuevas relaciones sociales. Implica la alteración de la normalidad, cuestionando el conformismo establecido, modificando las resignaciones y criterios morales constituidos.

Esos movimientos estratégicos y tácticos, en un sentido ético-político, alteran las subalternidades, rompen lo establecido, lo natural, construyen conciencia y procesos pedagógicos emancipatorios. Los estados de situación que así se van construyendo se presentan como irreverentes para los sectores dominantes. Contienen la construcción colectiva de organizaciones que enlaza en un mismo movimiento voluntades y creatividades transformadoras, que potencian al mismo tiempo los procesos de conciencia de la dimensión histórico-concreta de la sociedad. La ruptura de la rutina familiarizada habilita la construcción del hecho histórico, el cuestionamiento a los dispositivos de dominación. Se define un tiempo y espacio de transformación.

Es un proceso múltiple, de un conjunto creativo de experiencias, de participación, de aprendizajes colectivos, de involucramientos y aprendizajes compartidos, con temporalidades y espacios diferentes pero articulados, heterogéneos, pero operantes en un sentido ético-político. Se cuestionan las autoridades y direcciones establecidas. Se disputa una nueva autoridad ética moral. Se configuran mayorías movilizadas, dispuestas a difundir una nueva concepción del mundo y a enfrentar luchas decisivas, que pongan en cuestión las relaciones fundamentales de la sociedad.

En síntesis, la revolución es construir fuerza desde abajo, inventar una nueva sociedad. Romper la apatía, la resignación, politizar lo establecido y construir horizontes de transformación. Implica articular diversas temporalidades, politizando el presente, enlazando reformas en un sentido transformador, en un sentido de emancipación humana. ${ }^{15}$ La complejidad de esta tarea, que involucra diferentes configuraciones históricas de relaciones de fuerza en el movimiento de la sociedad, subraya la necesidad de comprender la cuestión de la revolución como proceso y su relación táctica con reformas que se articulen en la construcción de una nueva hegemonía. Esto nos exige romper mistificaciones y abstracciones, entendiendo la dimensión singular y particular de cada proceso. 


\section{REFERENCIAS}

ANDERSON, P. Neoliberalismo: un balance provisório. In SADER, E.; GENTILI, P. La trama del neoliberalismo: mercado, crisis y exclusión social. 1. ed. Buenos Aires: Oficina de publicaciones del CBCUBA, 1997 .

BORON, A. A. La selva y la polis: reflexiones en torno a la teoría política del zapatismo. Revista OSAL, Buenos Aires, n. 3, p. 177-186, 2001.

BORÓN, A. Estado, capitalismo y democracia en América Latina. Buenos Aires: CLACSO, 2003.

CECEÑA, A. E. El zapatismo: de la inclusión en la nación al mundo en el que quepan todos los mundos. In GÓMEZ, J. M. (comp.). América Latina y el (des)orden global neoliberal. Buenos Aires: CLACSO, 2004.

FERNÁNDEZ SOTO, S. Políticas sociales y proyectos de sociedad: Crisis, neoliberalismo y reconfiguración "neodesarrollista" en Argentina en el siglo XXI. Revista Políticas Públicas, São Luís, v. 17, n. 2, p. 367-388, 2013.

GARCÍA LINERA, Á.; TAPIA, L.; PRADA, R. La transformación pluralista del Estado. La Paz: Muela del diablo, 2007.

GRAMSCI, A. Antología. México: Siglo XXI, 1988.

GRAMSCI, A. Cuadernos de la cárcel. México: Juan Pablos Editor, 1990.

GRAMSCI, A. El materialismo histórico y la filosofía de benedeto croce. México: Juan Pablos Editor, 1986.

GRAMSCI, A. Notas sobre maquiavelo, sobre la política y sobre el estado moderno. Buenos Aires: Editorial Nueva Visión, 1998.

GRÜNER E. La oscuridad y las luces: capitalismo, cultura y revolución. Buenos Aires: Editorial edhasa, 2010. HARVEY, D. El 'nuevo' imperialismo: acumulación por desposesión. Revista Socialist Register, Buenos Aires, p. 99-129, 2004.

HARVEY, D. El nuevo imperialismo. Madrid: Akal Ediciones, 2007a.

HARVEY, D. Espacios de esperanza. Madrid: Akal Ediciones, 2007b.

HARVEY, D. Espacios del capital: hacia una geografía crítica. Madrid: Akal Ediciones, 2011

HOLLOWAY, J. El zapatismo y las ciencias sociales en América Latina. Revista OSAL, Buenos Aires, n. 3, p.171-176, 2001.

INIIGO CARRERA, N.; COTARELO, M. C. Algunos rasgos de la rebelión en la Argentina 1993-2001. Buenos Aires: PIMSA. 2004. PIMSA Documentos y comunicaciones. 
MARINI R. M. Dialéctica de la dependencia. México: Ediciones Era, 1973

MARINI R. M. Dialéctica de la dependencia: la economía exportadora. Sociedad y Desarrollo, [S. I.], n. 2, p. 35-51, 1972.

MARINI R. M. Las razones del neodesarrollismo (o porqué me ufano de mi burguesía). Revista Mexicana de Sociología, México, n. 78, p.57-106, 1978.

MARINI R. M. Proceso y tendencias de la globalización capitalista. In MARINI, R. M.; MILLÁN, M. (coords.). La teoría social latinoamericana: cuestiones contemporáneas. México: UNAM/ Ediciones El Caballito S.A., 1996. Tomo IV.

MARX, C. La cuestión judía. Buenos Aires: Planeta-Agostini, 1992.

MODONESI, M. Crisis hegemónica y movimientos antagonistas en América Latina: una lectura gramsciana del cambio de época. Revista Contra Corriente, México, v. 5, n. 2, p. 115-140, 2008. Disponível em: http://www.rebelion.org/noticia.php?id=73350. Acesso em: 12 nov. 2011.

OSORIO J. La cuestión latinoamericana, en Estudios Latinoamericanos. Nueva Época, México, n. 34, p.23-48, 2014.

PORTO GONÇALVES, C. W. A nova questão agrária e a reinvenção do campesinato: 0 caso do MST.

Revista OSAL, Buenos Aires, n. 16, p. 23-24, 2005.

PRADA, R. Horizontes del Estado Plurinacional. In AA.VV. Más allá del desarrollo. Quito: Abya Yala. 2011.

QUIJANO, A. El movimiento indígena y las cuestiones pendientes en América Latina. In QUIJANO, A.

Cuestiones y horizontes. Buenos Aires: CLACSO, 2014

ZIBECHI, R. Los movimientos sociales latinoamericanos: tendencias y desafíos. Revista OSAL, Buenos Aires, n. 9, p. 185-188, 2003.

Notas

${ }^{1}$ La inserción de la región en el capitalismo global es resultado de un proceso permanente de (re)territorialización que involucra la producción de diferencias geográficas y la producción de escala espacial. Esto nos señala que la organización y articulación espacial mundo, no es estática ni natural. Es resultado de relaciones históricas concretas. Harvey (La inserción de la región en el capitalismo global es resultado de un proceso permanente de (re)territorialización que involucra la producción de diferencias geográficas y la producción de escala espacial. Esto nos señala que la organización y articulación espacial mundo, no es estática ni natural. Es resultado de relaciones históricas concretas. (HARVEY, 2007b, 2011) .

2 El 1 de enero de 1959 se desarrolla en Cuba una huelga general insurreccional que confirma la victoria de la revolución, convocada por Fidel Castro y el Movimiento 26 de julio y las organizaciones revolucionarias del país. Sin dudas en este proceso "[...] la Revolución Cubana fue una puesta al día de las viejas tesis leninistas, al poner de manifiesto la actualidad de la revolución en la etapa imperialista; la condición de eslabón débil de la periferia; la necesidad de incorporar las reformas democrático-burguesas como parte de la revolución socialista; además de los problemas de sobrevivencia de la revolución reducida a Estados nacionales, y de la construcción socialista en tales ámbitos." (OSORIO, 2014, p. 36).

${ }^{3}$ Se abre un nuevo período en las luchas de América Latina y el Caribe; expresadas claramente en las luchas anti- imperialistas y antidictatoriales de la región; como se observa contra las dictaduras de Somoza, Duvalier y Trujillo. 


\section{Silvia Fernández Soto}

${ }_{4}$ Experiencias de cambio, que pueden ser comprendidas en términos de reformas, estrategias de ciudadanización, en términos gramscianos de revoluciones pasivas, que incorporan demandas de las clases trabajadores en el marco de la institucionalidad estatal.

${ }^{5}$ Entre otras, podemos señalar la experiencia anti-imperialista, nacionalista y popular de Lázaro Cárdenas en México entre 19341940. Teniendo cierta continuidad con el gobierno de Miguel Avila Camacho (1941-1946). También podemos señalar el gobierno nacional-popular de Getulio Vargas, de Brasil (1930-1945), Juan Antonio Ríos en Chile (1942-46). En 1942 asume en Colombia el liberal progresista Alfonso López Purmarejo. En Argentina, se desarrolló la experiencia nacional y popular peronista, con las presidencias de Juan Domingo Perón entre 1946-1955. En Bolivia, en 1943, asume el mayor Gualberto Villarroel (1943-46). El conjunto de esas experiencias, con sus particularidades, expresaron cambios introducidos desde el Estado, se desarrollaron experiencias de industrialización bajo la perspectiva de sustitución de importaciones, se introdujeron diversas medidas de ampliación de la participación política y mejoramiento de las condiciones de vida de la población, a través de la ampliación y complejización de los Estados, institucionalizando garantías sociales fruto de reclamos de las clases trabajadoras y las transformaciones de los procesos de urbanización capitalista.

${ }^{6}$ Con la experiencia de múltiples dictaduras en el cono sur, en Centroamérica triunfa en Nicaragua la Revolución Sandinista en 1979, y se despliegan enfrentamientos en niveles de guerra civil en El Salvador y Guatemala en los años ochenta, procesos que fueron derrocados por las fuerzas imperialistas. Eso expresaba el cierre del ciclo abierto con la Revolución Cubana y anunciaba el despliegue del periodo contrarrevolucionario con la extensión de dictaduras cívico-militares.

7 En 1971 se produce un golpe de Estado contra el gobierno de Juan José Torres en Bolivia, con asesinatos, persecuciones, el cierre de la universidad, la intervención de los medios de comunicación, exilio de opositores políticos, desapariciones. En 1972 se impone en Salvador la tiranía de Armando Molina en el Salvador. En 1973 atacan y destituyen el gobierno socialista de Salvador Allende en Chile, instaurándose la dictadura de Augusto Pinochet, generando exiliados, detenciones, torturas, persecuciones a los opositores, allanamientos de partidos políticos y organizaciones obreras. En Uruguay se produce un autogolpe de Estado en 1973. En Argentina, el 24 de marzo de 1976, se impone el llamado Proceso de Reorganización Militar, encabezado por el general Jorge Videla, con el respaldo de las clases dominantes de las empresas transnacionales. Esas dictaduras implicaron sistemáticas violaciones a los derechos humanos, sociales, económicos, políticos y libertades fundamentales. Fueron propulsoras de las políticas neoliberales, seguidores de los fundamentos de la escuela monetarista de Chicago. Impusieron por la fuerza y el terror un proyecto de sociedad más desigual en enclave con los procesos de dominación oligárquicos-imperialistas, reconfigurando las relaciones internacionales en la región.

8 La incrustación en el aparato de Estado de un gobierno-enclave-popular y el intento de transformar la sociedad sin romper con la institucionalidad vigente, fórmula calificada como la vía chilena al socialismo. "Decenas de importantes fábricas pasan a manos estatales y quedan bajo gestión de sus trabajadores; los grandes yacimientos de cobre, así como 'el salario de Chile', antes en manos de importantes firmas estadounidenses, son nacionalizados; en tanto en fábricas, 'fundos', escuelas y poblaciones, los obreros, campesinos, trabajadores urbanos, estudiantes y pobladores discuten y dan pasos para asumir mayores responsabilidades en el curso de la vida productiva y política del país. En pocos meses el país se convierte en una sociedad movilizada, en constante organización y reorganización, y en creciente politización. También en una sociedad cada vez más polarizada en términos políticos." (OSORIO, 2014, p. 29).

9 Las cristalizaciones más relevantes de este diversificado proceso se alcanza en la conformación y accionar del Ejercito Zapatista de Liberación Nacional (EZLN) en México en sus primeros años y en la irrupción de un significativo movimiento indígena; en el Movimiento de los Sin Tierra en Brasil (MST); en la masiva sublevación popular que derrumba al gobierno de Fernando de la Rúa en Argentina; en las movilizaciones indígenas en Bolivia y Ecuador en defensa del agua, tierras y que derriban a diversos gobiernos neoliberales; en la resistencia popular en Venezuela y Honduras frente a golpes contrainsurgentes; en la llamada comuna de Oaxaca, en México; en la asunción de gobiernos populares en Bolivia y Venezuela y en las masivas y perdurables movilizaciones de estudiantes en Chile por educación gratuita y de calidad. Para esas cuestiones de resistencias, movimiento y propuestas, véase: Quijano (2014), Prada (2011), Ceceña (2004), Holloway (2001), Boron (2001), Porto Gonçalves (2005), Zibechi (2003), Iñigo Carrera y Cotarelo (2004) y García Linera, Tapia y Prada (2007).

10 En México, al final del gobierno del presidente Salinas de Gortari, en enero de 1994, emergió el movimiento zapatista, que se ha venido desarrollando desde entonces. Hay consenso en ubicar esta fecha como el comienzo explícito de resistencia anti- 
neoliberal. En Venezuela se produjeron movilizaciones populares contra los gobiernos de Carlos Andrés Pérez y de Rafael Caldera; los partidos políticos tradicionales colapsaron y se organizó y desarrolló el movimiento bolivariano, en el gobierno desde 1998. En Brasil, el presidente Collor de Mello fue destituido con movilizaciones populares cuya consigna principal era Fora Collor, denunciando la corrupción del gobierno. En Ecuador las movilizaciones populares provocaron la caída de varios gobiernos, siendo allí fundamental el papel del movimiento indígena y campesino, a través del Pachacutik. En Perú, el presidente Fujimori renunció y debió irse del país, luego de importantes movilizaciones populares, como las Marchas de los Cuatro Suyos. En Bolivia, debió renunciar Sánchez de Losada (2003) en medio de una intensa movilización popular encabezada por distintas organizaciones campesinas, indígenas y obreras, y, posteriormente, Carlos Mesa (2005). En Argentina, a fines del 2001, renuncia el presidente De la Rua, en el marco de movilizaciones populares con la consigna que se vayan todos. A esos procesos destituyentes de movilización popular expresados en la región latinoamericana, podemos señalar también la multitudinaria caravana zapatista por la dignidad indígena en México (2001), la resistencia popular victoriosa al intento de golpe de estado en Venezuela (2002) y la confrontación que posteriormente le siguió y, en el plano continental, la derrota relativa del proyecto del ALCA en la III Cumbre de las Américas (2005) en Mar del Plata (Argentina).

11 "La lucha de clases comenzó a condensarse en torno a cuestiones como el ajuste estructural impuesto por el FMI, las actividades depredadoras del capital financiero y la pérdida de derechos ocasionada por la privatización. El antimperialismo comenzó a convertirse en antagonismo contra los principales agentes de la financierización, el FMl, y el Banco Mundial." (HARVEY, 2007b, 65).

12 No es objeto de este trabajo analizar el significado socio-histórico de esas experiencias. Para ello véase un trabajo anterior, Fernández Soto (2013).

${ }^{13}$ El análisis de ese proceso histórico a través de la perspectiva gramsciana nos permite aprehender el principio de totalidad histórica en la relación Estado-sociedad; principio fundamental para comprender los dispositivos técnico-instrumentales diseñados en la trama conflictiva de las relaciones sociales fundamentales para afrontar manifestaciones de la cuestión social. Nos permite, al mismo tiempo, observar la materialidad de los procesos de organización de la cultura, a partir de la unidad orgánica de estructura-superestructura sobre la hegemonía de una determinada clase social, que en el proceso histórico referido al americanismo expresa la hegemonía de la burguesía industrial. El americanismo constituye un proceso de desarrollo de una modalidad de hegemonía del capital monopólico en su fase imperialista. Implica la concreción de una revolución pasiva, es decir, cambios en las formas de organización de la vida estatal, que tienden a metabolizar las fuerzas opositoras al orden establecido. Esos cambios del fenómeno estatal se producen a través de lo que Gramsci denomina el transformismo. Es a partir de esa perspectiva integral que Gramsci se preocupa por desentrañar los procesos sociales bajo los cuales se construye la hegemonía entendida como dirección intelectual y moral, operando en el campo ideológico cultural desde donde se construye el consenso social. (GRAMSCI, 1998, 1986).

14 Las reflexiones gramscianas se dirigen en el sentido de superar la situación de subalternidad, para lo cual es necesario construir tal como hemos señalado, conciencia del significado de la propia acción, de las posiciones de clase, de las jerarquías y desigualdades sociales presentes en la sociedad capitalista. Conciencia que se va construyendo en el propio proceso de elaboración, de abajo hacia arriba, de una nueva concepción del mundo, lo cual implica una nueva concepción de hombre, de Estado, de sociedad; a través de una voluntad colectiva que sostenga una práctica política de cambio de las relaciones fundamentales existentes. Véase Gramsci $(1988,1998,1990)$.

15 En 1843 Marx señalaba en la obra La Cuestión Judía que: "Sólo cuando el hombre (mujer) real, individual reabsorba en sí mismo(a) al ciudadano(a) abstracto y, como hombre (mujer) individual, exista a nivel de especie en su vida empírica, en su trabajo individual, en sus relaciones individuales; sólo cuando, habiendo reconocido y organizado sus <fuerzas propias> como fuerzas sociales, ya no separe de sí la fuerza social en forma de fuerza política, sólo entonces, se habrá cumplido la emancipación humana." (MARX, 1992, p. 52). 